\title{
INFLUENCE OF THE INITIAL GRAIN SIZE ON THE ROLLING AND RECRYSTALLIZATION TEXTURES IN THE ALLOY AL-1.8\% CU
}

\author{
O. ENGLER \\ Institut für Metallkunde und Metallphysik, RWTH Aachen, D-52056 Aachen
}

(Received 22 September 1994)

\begin{abstract}
The influence of the initial grain size prior to deformation on the rolling and recrystallization textures is investigated in the alloy $\mathrm{Al}-1.8 \mathrm{wt} \% \mathrm{Cu}$ by $\mathrm{X}$-ray macrotexture analysis. Two different particle stages are examined: (i) Small shearable precipitates give rise to shear band formation and, during annealing, to nucleation of recrystallization at shear bands. (ii) Large particles cause particle stimulated nucleation of recrystallization (PSN). The microstructural evolution, particularly during recrystallization nucleation, is elucidated by metallographical investigations supported by EBSD local texture analysis.

Both the initial grain size and the precipitation state strongly influence the evolution of the rolling textures. The results are interpreted with the help of Taylor-type deformation models. The recrystallization textures of $\mathrm{Al}$-alloys emerge from a superposition of the orientations stemming from the various nucleation sites, i.e. Cube-bands, shear bands and particles. An increase of the initial grain size prior to deformation substantially shifts the recrystallization texture from the Cube-orientation towards the orientations being attributed to the other nucleation sites (shear bands, particles) which is interpreted by the spatial density of the various nucleation sites.
\end{abstract}

KEY WORDS: Initial grain size, rolling textures, recrystallization textures, $\mathrm{Al}-1.8 \% \mathrm{Cu}$, Cube-bands, shear bands, PSN, EBSD, Taylor models.

\section{INTRODUCTION}

The formation of the crystallographic texture after cold rolling and subsequent recrystallization annealing can be interpreted by the two fundamental physical mechanisms, formation of recrystallization nuclei and subsequent growth of the nuclei into the deformed matrix. In some cases one of these two processes dominates the formation of the recrystallization textures; i.e. either very many nuclei of a certain orientation are formed or grains of a given orientation are favoured by a very large growth rate. Thus two limit cases in explaining recrystallization textures can be distinguished: (i) Oriented nucleation: Here it is assumed that the preferred nucleation of some special orientations determines the texture. (ii) Oriented growth: Here it is assumed that out of a broad spectrum of orientations of nuclei those with the best growth conditions with respect to the surrounding deformed matrix will determine the recrystallization texture. In $\mathrm{Al}$ a $40^{\circ}<111>$ orientation relationship to the deformed matrix was found to lead to highest growth rates (Lücke 1974). Most recrystallization textures of Al-alloys, however, have to be explained by a combination of these two mechanisms, in the sense of growth selection out of a limited spectrum of preferred nucleation sites. 
The typical recrystallization texture of pure $\mathrm{Al}$ is the Cube-texture (e.g. Juul Jensen et al. 1986, Hirsch and Lücke 1986, Hjelen et al. 1993). In Al-alloys, however, a great variety of different recrystallization texture components shows up, depending on details of the deformed microstructure (deformation inhomogeneities, initial texture, etc.) as well as on the composition of the alloy, the corresponding precipitation state, and on the recrystallization temperature (e.g. Juul Jensen $e t$ al. 1988, Lücke and Engler 1990, 1992).

The evolution of the recrystallization texture of cold rolled binary $\mathrm{Al}-1.8 \% \mathrm{Cu}$ with different precipitation states was investigated in a recent publication by Engler et al. (1995). The resulting recrystallization textures could be subdivided into four different types, which are characterized by several specific orientations ${ }^{1}$ ). These four types of recrystallization textures shall now briefly be reviewed:

$R 1$. The recrystallization textures of supersaturated samples which depict homogeneous deformation comprise the Cube-orientation with strong scattering. Since the deformation mode is similar to that of pure $\mathrm{Al}$, the nucleation of recrystallization is assumed to be similar as well. It is generally accepted that nuclei with Cube- and particularly with rotated Cube-orientation emerge from band-like structures present in the deformed microstructure (e.g. Dons and Nes 1986, Hjelen et al. 1991, Doherty et al. 1993, Engler et al. 1995b). However, it is still open to discussion whether these bands are either transition bands according to the mechanism proposed by Dillamore and Katoh (1974) or grain boundaries to deformed grains which comprise a Cubeorientation retained from the initial texture. During the subsequent growth of these nuclei the exact Cube-orientation prevails due to its pronounced compromise character $\left(40^{\circ}\right.$ $<111>$ orientation relationship to all symmetrically equivalent components of the rolling texture; Hirsch and Lücke 1986). Often also the R-orientation is obtained, which has

Table 1 Euler angles and Miller indices of the most important orientations observed in this investigation.

\begin{tabular}{|c|c|c|c|c|c|}
\hline & Notation & $\varphi_{1}$ & ${ }_{\phi}^{\text {ang }}$ & $\varphi_{2}$ & $\begin{array}{l}\text { Miller indices** } \\
\{h k l\}<u v w>\end{array}$ \\
\hline Rolling & $\begin{array}{l}\text { C } \\
\text { S } \\
\text { B }\end{array}$ & $\begin{array}{l}90^{\circ} \\
59^{\circ} \\
35^{\circ}\end{array}$ & $\begin{array}{l}30^{\circ} \\
33^{\circ} \\
45^{\circ}\end{array}$ & $\begin{array}{l}45^{\circ} \\
65^{\circ} \\
0^{\circ} / 90^{\circ}\end{array}$ & $\begin{array}{l}\{225\}<554> \\
\{123\}<634> \\
\{011\}<211>\end{array}$ \\
\hline Recrystallization & $\begin{array}{l}\text { Goss } \\
\text { Cube } \\
\text { Cube }_{\text {ND }} \\
\text { Cube }_{\text {RD }} \\
\text { R } \\
\mathbf{Q} \\
\text { P }\end{array}$ & $\begin{array}{l}0^{\circ} \\
0^{\circ} \\
22^{\circ} \\
0^{\circ} \\
63^{\circ} \\
45^{\circ} \\
70^{\circ}\end{array}$ & $\begin{array}{l}45^{\circ} \\
0^{\circ} \\
0^{\circ} \\
22^{\circ} \\
31^{\circ} \\
15^{\circ} \\
45^{\circ}\end{array}$ & $\begin{array}{l}0^{\circ} / 90^{\circ} \\
0^{\circ} / 90^{\circ} \\
0^{\circ} / 90^{\circ} \\
0^{\circ} / 90^{\circ} \\
60^{\circ} \\
10^{\circ} \\
0^{\circ} / 90^{\circ}\end{array}$ & $\begin{array}{l}\{011\}<100> \\
\{001\}<100> \\
\{001\}<310> \\
\{013\}<100> \\
\{124\}<211> \\
\{013\}<231> \\
\{011\}<122>\end{array}$ \\
\hline
\end{tabular}

* as most frequently observed in this investigation

** approximated

\footnotetext{
1 Crystallographic orientations are denoted in the following by single letter abbreviations, the corresponding Euler-angles $\varphi_{1}, \phi, \varphi_{2}$ and Miller-indices $\{$ hkl $\}<u v w>$ are summarized in Table 1 .
} 
a $40^{\circ}<111>$ relationship to the main rolling texture orientations as well. The $R$ orientation has been assumed to nucleate at grain boundaries (Hirsch and Lücke 1986, Engler et al. 1995b).

$R 2$. In supersaturated or peak-aged samples which exhibit strong shear band formation, strong Goss-, Q- and P- components occur instead of Cube after recrystallization. These orientations nucleate in the shear bands, and their formation can be explained by a \pm TD-rotation of the main rolling texture components $C$ and $S$ that occurs during shear banding and further homogeneous deformation. Furthermore, these orientations are capable to grow under favourable conditions due to their $40^{\circ}$ $<111>$-orientation relationship to the main components of the rolling textures.

$R 3$. In samples containing larger particles $(>1 \mu \mathrm{m})$ annealed at high temperatures, nucleation takes place in the deformation zones around the particles (PSN; Humphreys 1977). Locally, the orientations of the subgrains in the deformation zones can be related to the corresponding matrix orientations, but with respect to the macrotexture a more or less random orientation distribution shows up. During the early stages of annealing micro growth selection of some preferred orientations out of this spectrum of PSNnuclei takes place (Engler et al. 1995b). This results in weak recrystallization textures comprising the P-orientation and a characteristic scatter of Cube about ND. So the resulting recrystallization textures can be again interpreted by a combination of oriented nucleation and growth selection.

In the presence of a fraction of very fine precipitates, additional effects have been observed, namely, depending on the strength of inhibition, either suppression of PSN or recrystallization in situ (R4). However, these effects are not relevant for the present investigation, and therefore, will not be treated here any further.

Conclusively, in the above mentioned investigation about the alloy $\mathrm{Al}-1.8 \% \mathrm{Cu}$ the recrystallization texture components could be definitely related to their respective nucleation sites, i.e. either Cube-bands (R1) or shear bands (R2) or the deformation zones around large particles (R3).

In a multitude of other Al-alloys the obtained recrystallization textures could be classified into this scheme of recrystallization texture types R1 to R4 that was originally established for $\mathrm{Al}-1.8 \% \mathrm{Cu}$ (e.g. Lücke and Engler 1990, 1992). However, even when in these materials shear bands or particles were active as nucleation sites, in most cases much stronger occupations of the Cube-orientation were found than in $\mathrm{Al}-1.8 \% \mathrm{Cu}$. Mostly only a weakening of the Cube-texture in Al-alloys containing large particles was reported (e.g. Bleck and Bunge 1981, Juul Jensen et al. 1985, Oscarsson 1987). The recrystallization texture of the alloy $\mathrm{Al}-1.3 \% \mathrm{Mn}$ containing large $(2-3 \mu \mathrm{m}) \mathrm{Al}_{6} \mathrm{Mn}$ precipitates was explained by a superposition of the PSN-orientations ( $\mathrm{Cube}_{\mathrm{ND}^{-}}$and $\mathrm{P}$ orientation; type R3) and the Cube-orientation which was proved to nucleate at Cubebands similar as in pure Al (R1) (Engler et al. 1995b).

With regard to nucleation at shear bands (type $\mathrm{R} 2$ ), in $\mathrm{Al}-3 \% \mathrm{Mg}$ exhibiting profuse shear band formation after rolling $98 \%$, the Cube-orientation was found to form the texture maximum with intensity values as high as $f(g)=53$, whereas the Goss- and Qorientations had grown to only $f(g)=12$ and $f(g)=8$, respectively (Wagner et al. 1990, Lücke and Engler 1992). Koken et al. (1988) observed nucleation at shear bands in $\mathrm{Al}-4.8 \% \mathrm{Mg}$, but described the microstructure after completed recrystallization as being determined by new grains nucleating at prior grain boundaries.

So in most examples stronger amounts of the Cube-orientation are observed than in $\mathrm{Al}-\mathrm{Cu}$ with comparable microstructural features. From these results it can be concluded that besides the nucleation mechanisms discussed above - shear bands (R2), 
particles (R3) - the nucleation mechanisms that are active in pure Al-alloys are in the given samples active as well. So in these cases nucleation at grain boundaries and at Cube-bands always occurs, giving rise to the strong Cube-orientation (R1). The resulting recrystallization textures are then caused by a superposition of the components stemming from the various nucleation sites and their-specific growth advantages.

In the following, in a first approach, it will be assumed that the influence of the alloying elements is restricted only to the formation of shear bands or precipitates and, consequently, to the potential nucleation sites. The growth behaviour, in contrast, shall not be affected, which at least for annealing temperatures beyond the solution temperature seems to be reasonable. (Of course this is not valid for the recrystallization kinetics.) With regard to this assumption the main difference between the samples of the alloy $\mathrm{Al}-1.8 \% \mathrm{Cu}$ and the above mentioned literature data then was the value of the initial grain size prior to cold rolling, which was quite large in case of $\mathrm{Al}-1.8 \% \mathrm{Cu}$ $(\sim 200 \mu \mathrm{m})$. It was the purpose of the present study to determine whether this difference in initial grain size can be accounted for in explaining the reduced Cube-intensity in the recrystallization textures of $\mathrm{Al}-1.8 \% \mathrm{Cu}$. For that, in samples of the same alloy $\mathrm{Al}$ $1.8 \% \mathrm{Cu}$, the initial grain size prior to deformation was systematically varied by a factor of 20. Furthermore, by variation of the pre-treatment of these samples, two different sample stages were produced, so that both mechanisms of recrystallization nucleation could be investigated, i.e. nucleation at shear bands (type R2) and particle stimulated nucleation (PSN; R3).

\section{EXPERIMENTAL PROCEDURE AND CHARACTERIZATION OF THE STARTING MATERIAL}

As explained in more detail elsewhere (Engler et al. 1989, 1995), a plate (10 mm thick) of a high purity $\mathrm{Al}-1.8 \mathrm{wt} \%(0.77 \mathrm{at} \%) \mathrm{Cu}$ alloy was treated by suitable pre-rolling and annealing at $480^{\circ} \mathrm{C}$ in order to achieve a recrystallized structure with $\mathrm{Cu}$ in supersaturated solid solution (solution temperature for $1.8 \% \mathrm{Cu} \mathrm{T}_{\mathrm{s}}=410^{\circ} \mathrm{C}$ ). In that specimen a grain size of $\sim 200 \mu \mathrm{m}$ and a texture close to random were obtained (Table 2 ). In the following these samples will be labelled as " $S$ " (standard).

In order to receive a smaller grain size in the same material, the specimen " $S$ " was cold rolled to $2.5 \mathrm{~mm}$ (75\% thickness reduction) and recrystallization annealed for $10 \mathrm{~s}$ at $450^{\circ} \mathrm{C}$ which yielded a grain size of $\sim 40 \mu \mathrm{m}$ (Table 2). This fine grained material will be referred to as " $F$ ". Furthermore, a sample " $C$ " with very coarse grains was produced by annealing the standard sample for $90 \mathrm{~min}$ at $475^{\circ} \mathrm{C}$. In that sample grain growth led to a grain size of $\sim 800 \mu \mathrm{m}$ (Table 2 ). In order to produce different precipitation

Table 2 Characterization of the starting material

\begin{tabular}{|c|c|c|c|c|c|}
\hline & \multicolumn{2}{|l|}{ Sample } & \multirow{2}{*}{$\frac{\text { "F" }}{42}$} & \multirow{2}{*}{$\frac{\text { “S” }}{206}$} & \multirow{2}{*}{ “C” } \\
\hline Initial grain size & & {$[\mu \mathrm{m}]$} & & & \\
\hline & Cube $_{\mathrm{ND}}$ & $M_{[}[\%]$ & 17.0 & 15.1 & 10.1 \\
\hline Initial & Cube $_{\text {RD }}$ & $\mathbf{M}_{i}[\%]$ & 8.5 & 9.0 & 9.8 \\
\hline \multirow[t]{2}{*}{ Texture } & Cube $_{\mathrm{TD}}$ & $\mathbf{M}_{[}[\%]$ & 4.0 & 5.8 & 11.0 \\
\hline & phon & $\mathbf{M}_{[}[\%]$ & 70.5 & 70.1 & 69.1 \\
\hline
\end{tabular}


stages, samples of specimens "F", " $S$ " and "C" were cut and aged in a salt bath at the temperature of $\mathrm{T}_{\mathrm{A}}=300^{\circ} \mathrm{C}$ as also discussed in more detail by Engler et al. (1989). One part of the specimens was annealed for 1 hour to precipitate many very finely distributed $\theta$ '-particles (series A1, "peak-aged", $\mathrm{H}_{\mathrm{v}} \approx 40$ ) which should ensure shear band formation during deformation. The other part was annealed for $100 \mathrm{~h}$ at $300^{\circ} \mathrm{C}$ to precipitate less but coarser $(>1 \mu \mathrm{m})$ particles (series A100, “overaged", $\mathrm{H}_{\mathrm{v}} \approx 23$ ) which should give rise to PSN during the recrystallization anneal.

These specimens were homogeneously cold rolled to various reduction degrees up to $97.5 \%$ thickness reduction. Subsequently, samples were taken from the rolled sheets and recrystallization annealed for $3 \mathrm{~s}$ in a salt bath at the temperature of $\mathrm{T}_{R}=450^{\circ} \mathrm{C}$. This temperature is above both the ageing temperature $T_{A}=300^{\circ} \mathrm{C}$ and the solution temperature $\mathrm{T}_{\mathrm{s}}=410^{\circ} \mathrm{C}$, so that effects of secondary precipitation during the recrystallization anneal could be avoided.

For all sample stages incomplete pole figures $\left(5^{\circ} \leq \alpha \leq 85^{\circ}\right)$ were measured by means of an automated X-ray texture goniometer (Hirsch et al., 1986) and corrected with respect to background irradiation and defocusing error. In order to enlarge the area encountered by X-rays in case of the coarse grained samples and so to improve statistics, pole figure data of several samples ( 2 to 5 ) were added prior to ODF calculation. ODFs $f(g)$ were calculated from four incomplete pole figures $(\{111\},\{200\},\{220\},\{311\})$ according to the series expansion method with $l_{\max }=22$ (Bunge 1969). All ODFs were ghost corrected by fitting them with Gauss-type scattering functions according to the method of Lücke et al. (1986).

Supplementary to macrotexture analysis, for samples A1 in a partially recrystallized stage orientations of individual recrystallized grains were measured by means of electron back scatter diffraction (EBSD) in a SEM (Engler and Gottstein, 1992). From the data ODFs were calculated by associating each single grain orientation with a Gauss-type scattering function in the Euler angle space (half scatter width $8^{\circ}$ ). The resulting ODFs could then be compared to those derived from the X-ray macrotexture measurements.

\section{RESULTS}

\subsection{Rolled samples}

First of all, the initial textures of all three samples " $F$ ", " $S$ " and " $C$ " were determined, the $\varphi_{2}=0^{\circ}$-sections of the corresponding ODFs are represented in Figure 1. In case of the coarse grained sample "C" the number of encountered grains was too low for sufficient statistics, although 5 specimens had been evaluated. However, in all samples very weak and rather similar initial textures with only minor occupations of a widely scattering Cube-orientation were obtained (Figure 1), which is in accordance with earlier results of this material. With increasing initial grain size ("F" $\rightarrow$ " $S$ " $\rightarrow$ " $C$ ") a slightly increasing tendency to form RD- and TD-scatter rather than ND-scatter of the Cubeorientation showed up. In order to depict this effect more quantitatively, the initial textures were decomposed into several individual orientations (Lücke et al. 1986). The resulting volume fractions of the rotated Cube-orientations as well as the random part of the textures (phon) are listed in Table 2.

After cold rolling all samples exhibited textures in which the orientations were concentrated along the $\beta$-fibre. This orientation-fibre is typical for fcc rolling textures; it runs through the Euler angle space from the $C$-orientation $\{112\}<111>$ over $S$ 


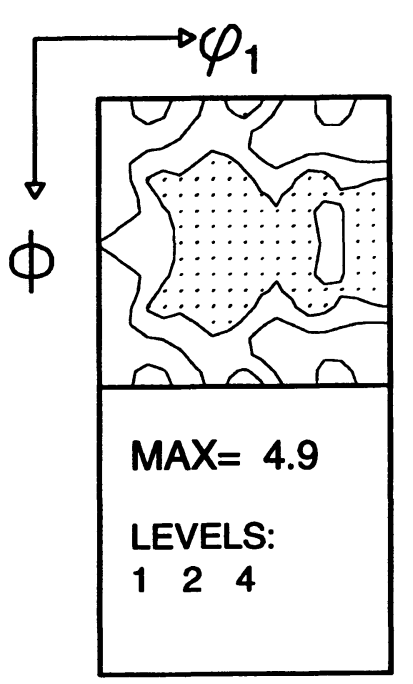

\section{(a) Sample "F"

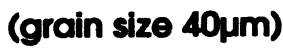
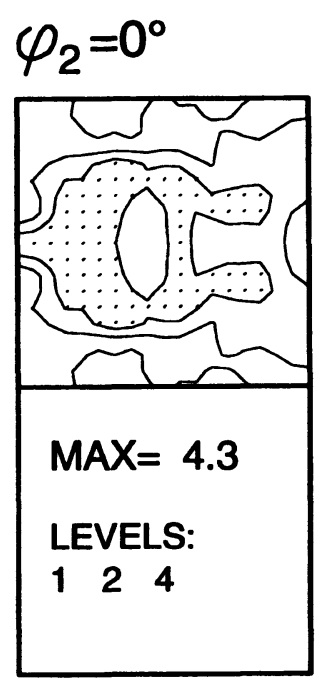

(b) Sample "S" (grain size 200um) compl. ODF

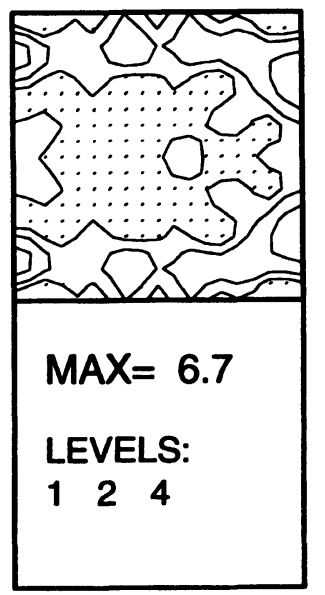

(c) Sample "C" (grain size 800um)

Figure 1 Initial textures of the three sample sets $\left(\varphi_{2}=0^{\circ}\right.$-sections) (a) "F", (b) "S", (c) "C"

$\{123\}<634>$ towards the B-orientation $\{011\}<211>$. The distribution of orientation densities along this fibre, however, strongly depends on the parameters rolling degree, precipitation state and initial grain size. These effects can best be followed by plotting the distribution of the orientation density $f(g)$ along the $\beta$-fibre versus the corresponding Euler angle $\varphi_{2}$. As an example, Figure $2 \mathrm{a}$ and $\mathrm{b}$ shows these $\beta$-fibre plots of samples "F", "S" and "C", rolled 75\% (open symbols) and 95\% (filled symbols), for the sample series $A 1$ and $A 100$, respectively. In Figure $2 c$ the exact position of the $\beta$-fibres in the Euler angle space is depicted, i.e. $\varphi_{1}=f\left(\varphi_{2}\right)$ and $\phi=f\left(\varphi_{2}\right)$ (only for the $95 \%$ rolled samples). This diagram yields interesting information about the deformation mode of the samples (see below).

For both series $\mathrm{A} 1$ and $\mathrm{A} 100$ at moderate deformations up to $75 \%$ rather similar $\beta$-fibres with a slight preference of the $\mathrm{C}$-orientation were found. With increasing initial grain size ("F" $\rightarrow$ "S" $\rightarrow$ " $C$ ") the general intensity of the $\beta$-fibre decreased. At higher deformations the general texture sharpness of both series strongly increased. For the samples of series A1 a significant orientation shift of the texture maximum away from the C-orientation (at $\varphi_{2}=45^{\circ}$ ) along the $\beta$-fibre occurred. Whereas for sample " $F$ " a maximum in the S-orientation was obtained $\left(\varphi_{2} \approx 65^{\circ}\right)$, in the other samples " $S$ " and "C" this shift even reached the B-orientation $\left(\varphi_{2}=90^{\circ}\right)$. Furthermore, in series A1 larger values of the initial grain size yielded weaker rolling textures as already observed for the lower reduction degrees. In contrast, in case of the samples A100 the texture maximum remained between the $\mathrm{C}$ - and S-orientation with some unsystematic scatter at the samples with large initial grain sizes. Moreover, the differences in the orientation density of the samples with the various initial grain sizes diminished with increasing deformation. 

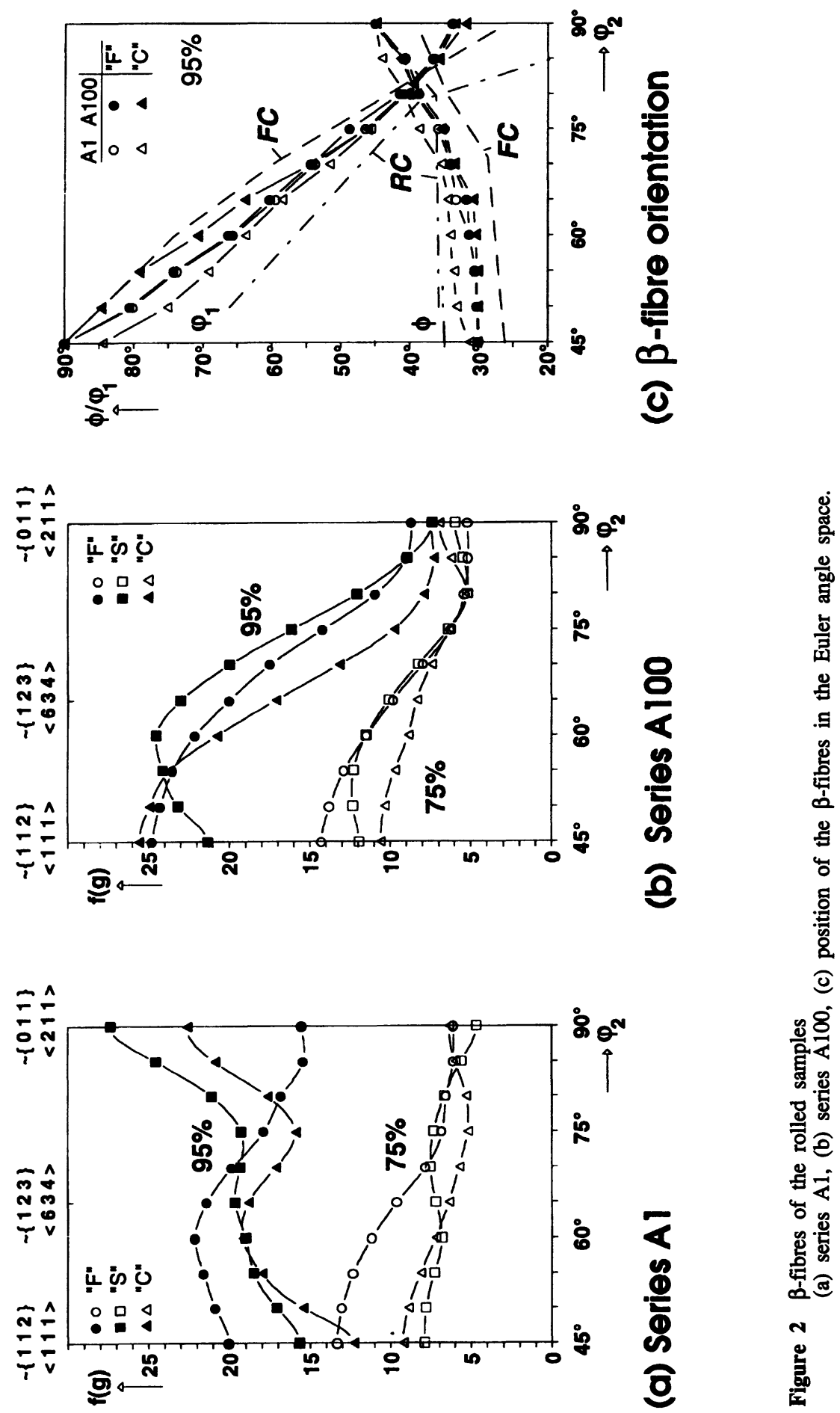

造 


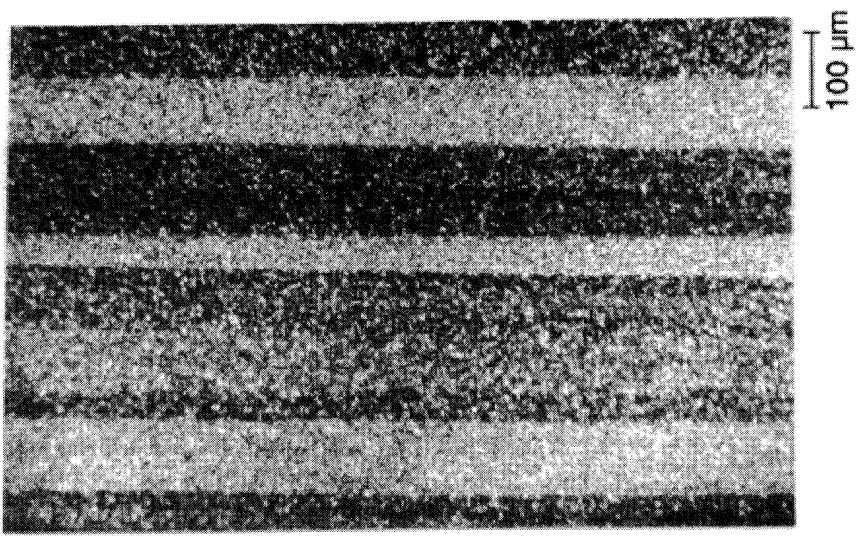

$\overline{0}$
$\frac{0}{4}$
$\frac{8}{\alpha}$
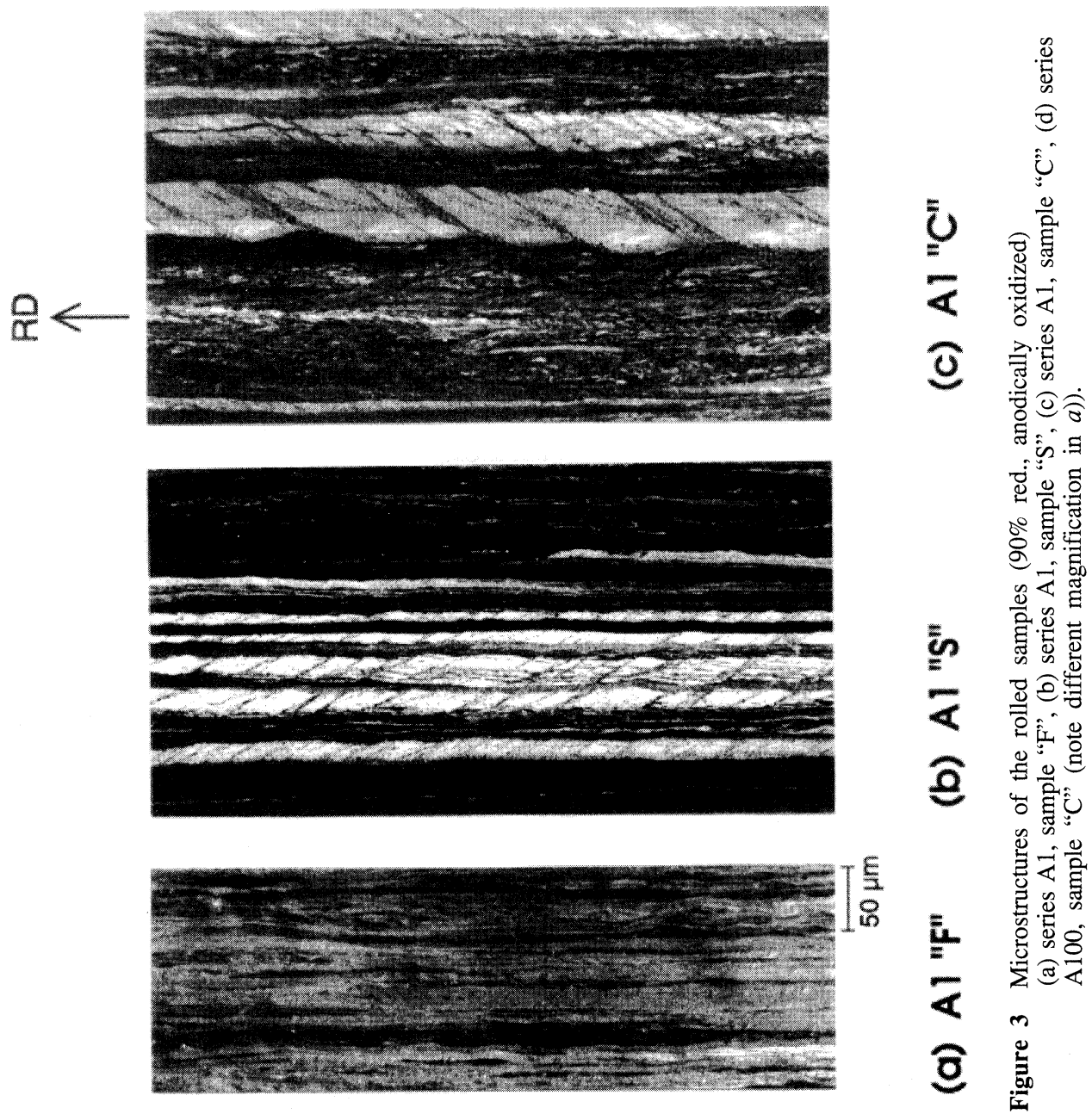
As examples of the microstructures after cold rolling, in Figure 3 micrographs of various samples after $90 \%$ reduction are depicted. (Unfortunately for the overaged samples A100 only poor micrographs could be obtained, which is due to the high density of the $\theta^{\prime}-\mathrm{Al}_{2} \mathrm{Cu}$-precipitates.) Whereas in sample $\mathrm{A} 100$ thick bands of homogeneously deformed grains were observed (Figure 3d), inhomogeneous deformation with profuse shear band formation prevailed in sample A1 (Figure 3a-c). The tendency to form shear bands substantially increased with initial grain size, as apparent from comparing density and length of the shear bands in the micrographs of samples " $F$ ", " $S$ " and "C" (Figure 3a-c). Particularly in the fine grained sample "F" only few shear bands formed (Figure 3a). It is interesting to note that the thickness of the deformed band exhibited strong scatter in all samples.

\subsection{Recrystallized samples}

Examples of the textures after recrystallization are depicted in Figures 4 and 5 for samples "F" and "C" of both series A1 and A100 for two reduction degrees. Results for samples " $S$ " can be found elsewhere (Engler et al. 1995). As for the rolling textures, similar types of recrystallization textures were obtained within each series. In the samples A1 rolled $97.5 \%$ peaks of the Goss-, Q- and P- orientations prevailed (type $\mathrm{R} 2, c f$. Sec. 1; Figure 4c,d). In the samples A100 the characteristic ND-rotated Cube-orientation and again the P-orientation were observed (R3, Figure 5c,d). At $90 \%$ reduction the differences between series $A 1$ and $A 100$ are less pronounced (Figures 4a,b, 5a,b). However, in both sample series it is obvious that the Cube-orientation is much stronger in the fine grained samples " $F$ " (Figures 4a,c,5a,c) compared to the standard samples "S" and the coarse grained samples " $C$ " (Figures 4b,d, 5b,d). In order to analyse the influence of initial grain size and rolling degree on the recrystallization textures more quantitatively, the volume fractions of the main texture components were computed (Figure 6). For these diagrams, the recrystallization texture components are classified as Cube-orientations (including RD-scattered Cube), random part of the texture (phon) and, for the peak-aged samples A1, those orientations which were attributed to nucleation at shear bands, i.e. Goss-, Q- and P- orientation (R2, Figure 6a,c). For the overaged samples A100, instead of the orientations formed at shear bands in series A1, those orientations which can be attributed to PSN, i.e. Cube $_{\mathrm{ND}}$ and P (R3) were considered (Figure 6b,d).

From these diagrams (Figure 6) it is obvious that with increasing initial grain size the volume fraction of the Cube-orientation substantially shrinks from $20 \%$ ("F") to less than 5\% ("C"). Vice versa the phon as well as the orientations ("Nucl.") being attributed either to nucleation at shear bands (A1) or at particles (A100) increase. Similarly, Juul Jensen et al. (1988) obtained much weaker textures with more random orientations in coarse grained Al-FeSi $(99.5 \%)$ after complete recrystallization. Furthermore, the results coincide with experimental findings by Sindel et al. (1990) and Duggan and Chung (1994), who reported that in pure $\mathrm{Cu}$ the intensity of the Cuberecrystallization texture was substantially enlarged when the initial grain size was smaller. With increasing degree of deformation the Cube-orientation decreases as well (Figure 6). This effect, however, is much less pronounced than that caused by the initial grain size.

The development of the microstructure during annealing was examined by light microscopy of anodically oxidized samples under polarized light. After complete 


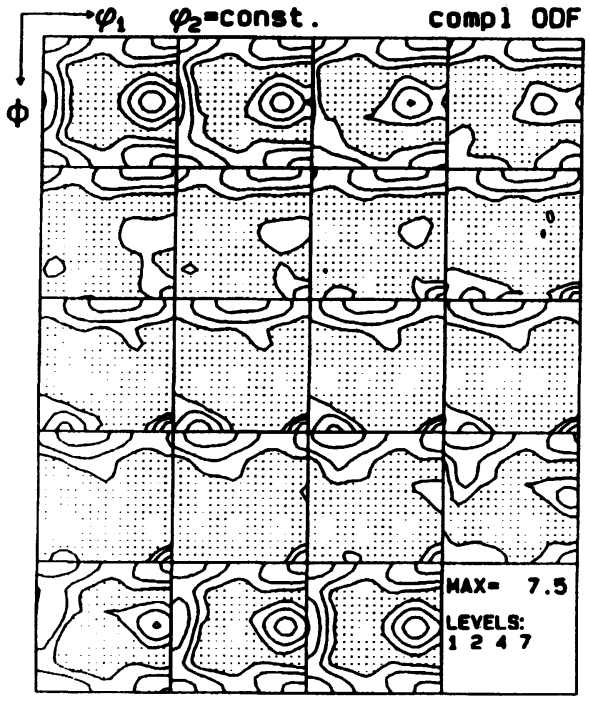

(a) "F", 90\% red.

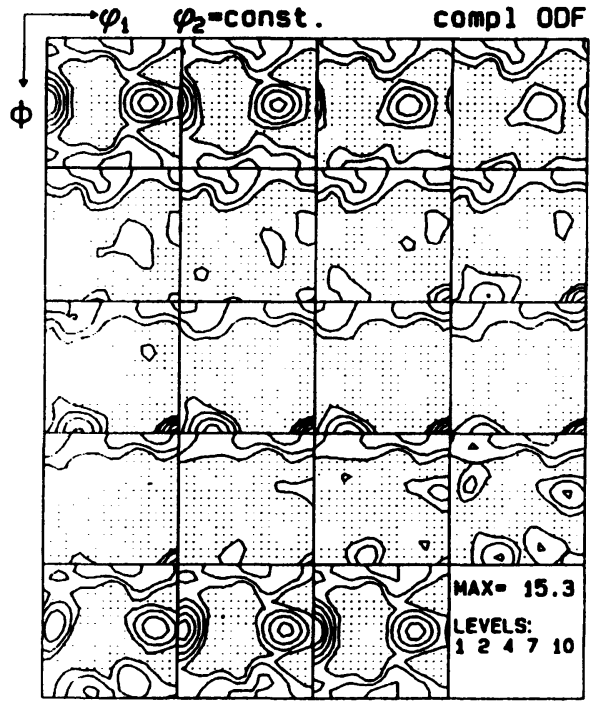

(c) "F", 97.5\% red.

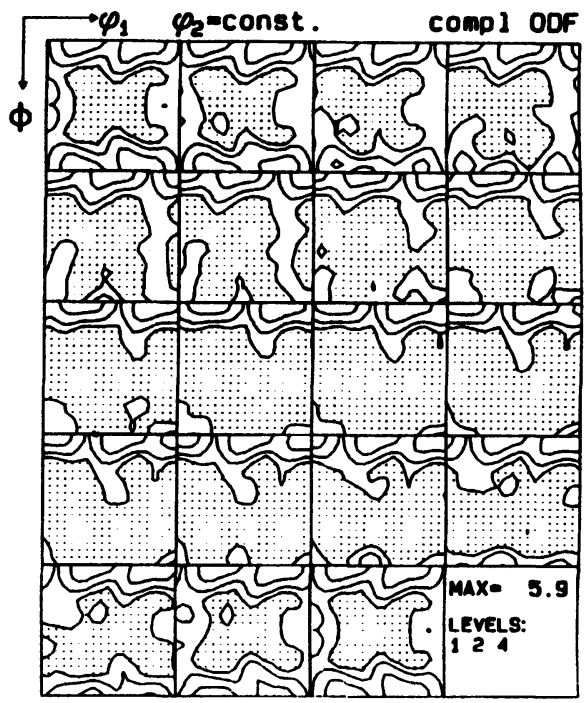

(b) "C", 90\% red.

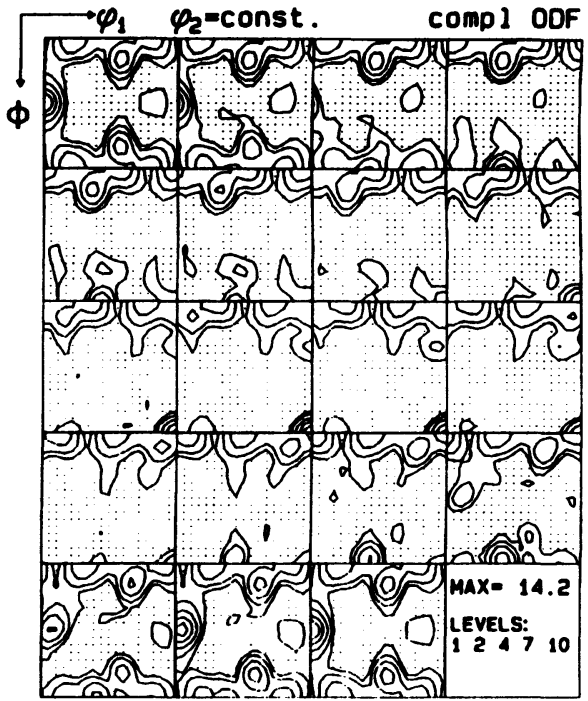

(d) "C", 97.5\% red.

Figure 4 ODFs of the recrystallization textures of the peak-aged samples A1

(a) sample "F", 90\% red., (b) sample "F", 97.5\% red.,

(c) sample "C", $90 \%$ red., (d) sample "C", $97.5 \%$ red. 


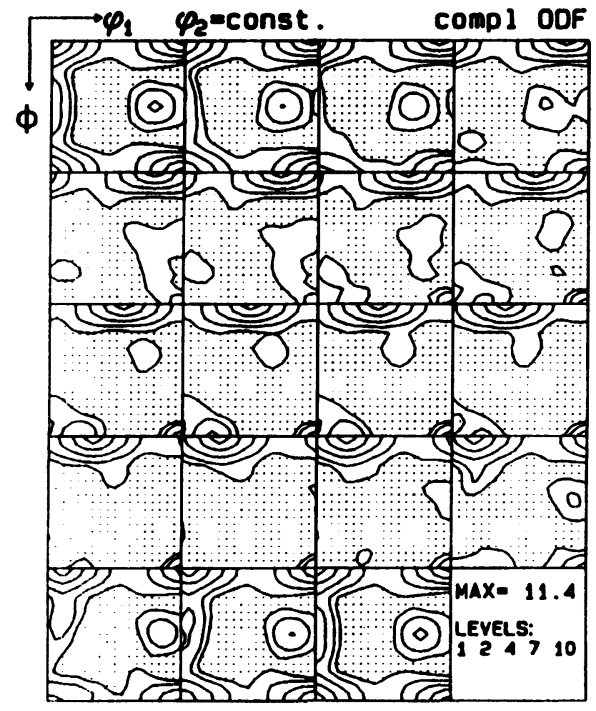

(a) "F", 90\% red.

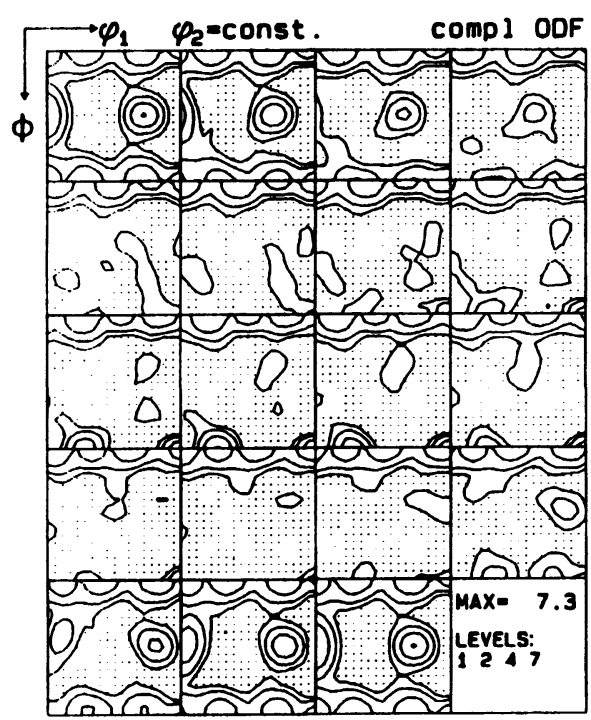

(c) "F", 97.5\% red.

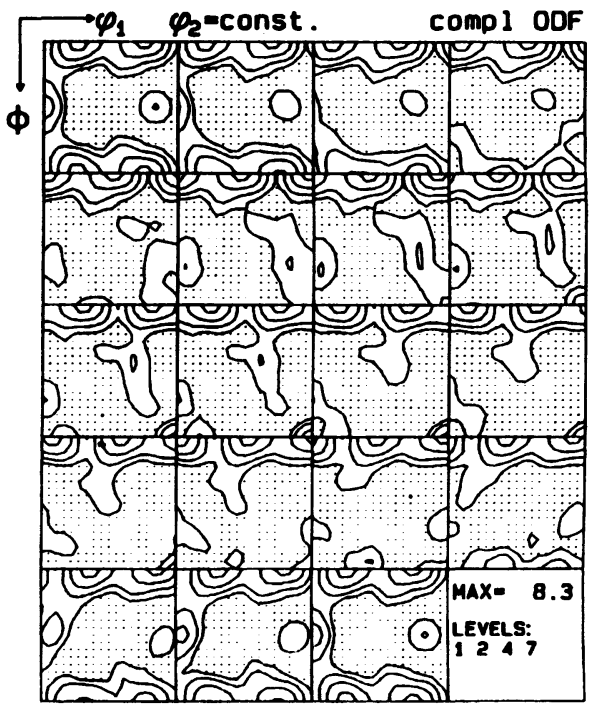

(b) "C", 90\% red.

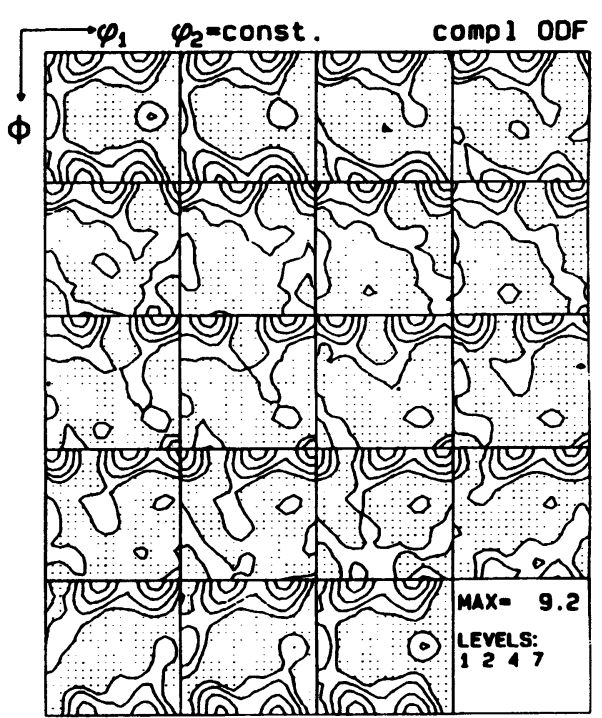

(d) "C", 97.5\% red.

Figure 5 ODFs of the recrystallization textures of the overaged samples A100

(a) sample "F", 90\% red., (b) sample " $F$ ", 97.5\% red.,

(c) sample "C", $90 \%$ red., (d) sample "C", $97.5 \%$ red. 


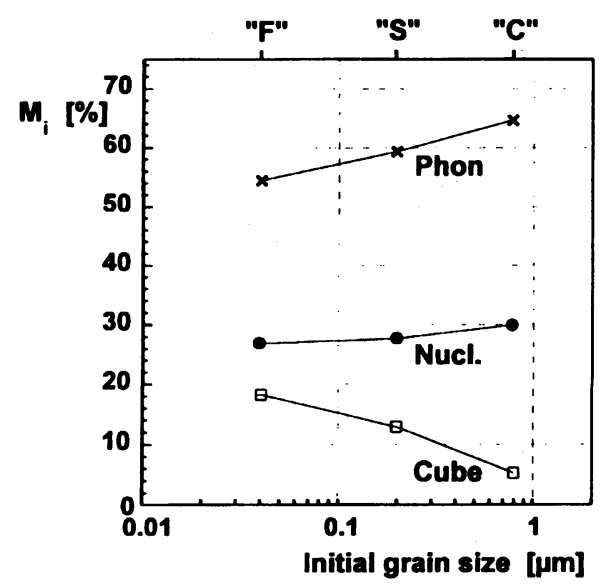

(a) Series A1, 90\% red.

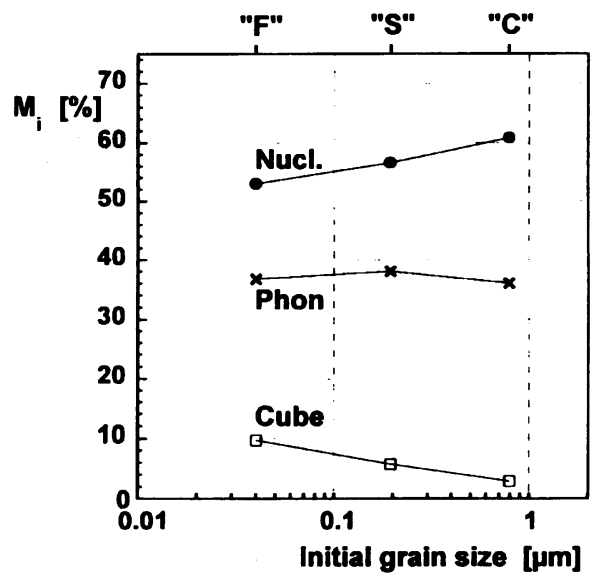

(c) Series A $1,97.5 \%$ red.

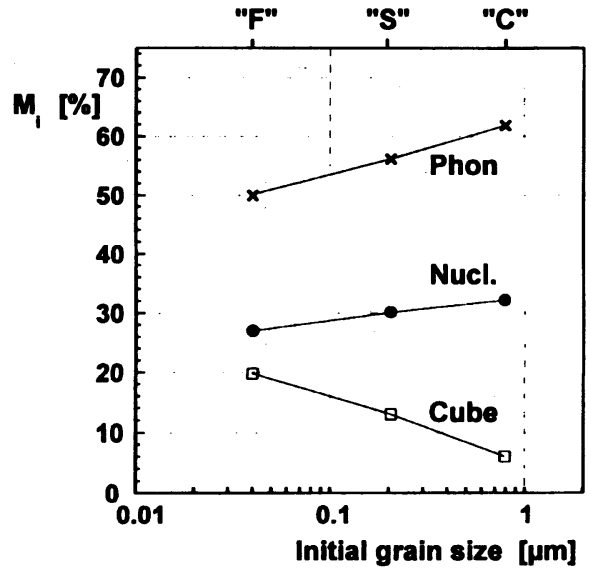

(b) Series A 100, 90\% red.

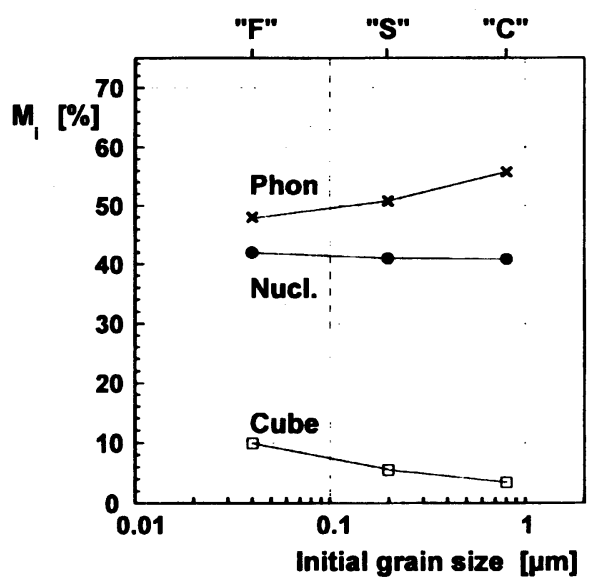

(d) Series A 100, $97.5 \%$ red.

Figure 6 Evolution of the volume fractions of the main recrystallization texture components at the various initial grain sizes

(a) series $\mathrm{A} 1,90 \%$ red., (b) series $\mathrm{A} 100,90 \%$ red.; (c) series $\mathrm{A} 1,97.5 \%$ red., (d) series A100, $97.5 \%$ red. 
recrystallization all samples exhibited a recrystallized structure comprising equiaxed grains (e.g. Figure 7a). The new grains depicted an average grain diameter of $\sim 33 \mu \mathrm{m}$ (series A1) and $\sim 24 \mu \mathrm{m}$ (series A100; after $90 \%$ rolling deformation). It must be emphasized that for both sample series A1 and A100 the values of the final grain size are not notably affected by the initial grain size prior to cold rolling!

In order to investigate the mechanisms of recrystallization nucleation, samples in a partially recrystallized stage had to be examined which, however, showed up to be very difficult owing to the fact that the time necessary for complete recrystallization was very short $(<3 \mathrm{~s})$. Figure $7 \mathrm{~b}$ shows an example of a partially recrystallized sample A1 "C", which had been deformed $90 \%$ and subsequently annealed for $\sim 1 \mathrm{~s}$ at $350^{\circ} \mathrm{C}$. As already expected, most new grains have obviously been nucleated at the shear bands, but some new grains were observed at band-like structures which are situated parallel to the rolling plane (see below).

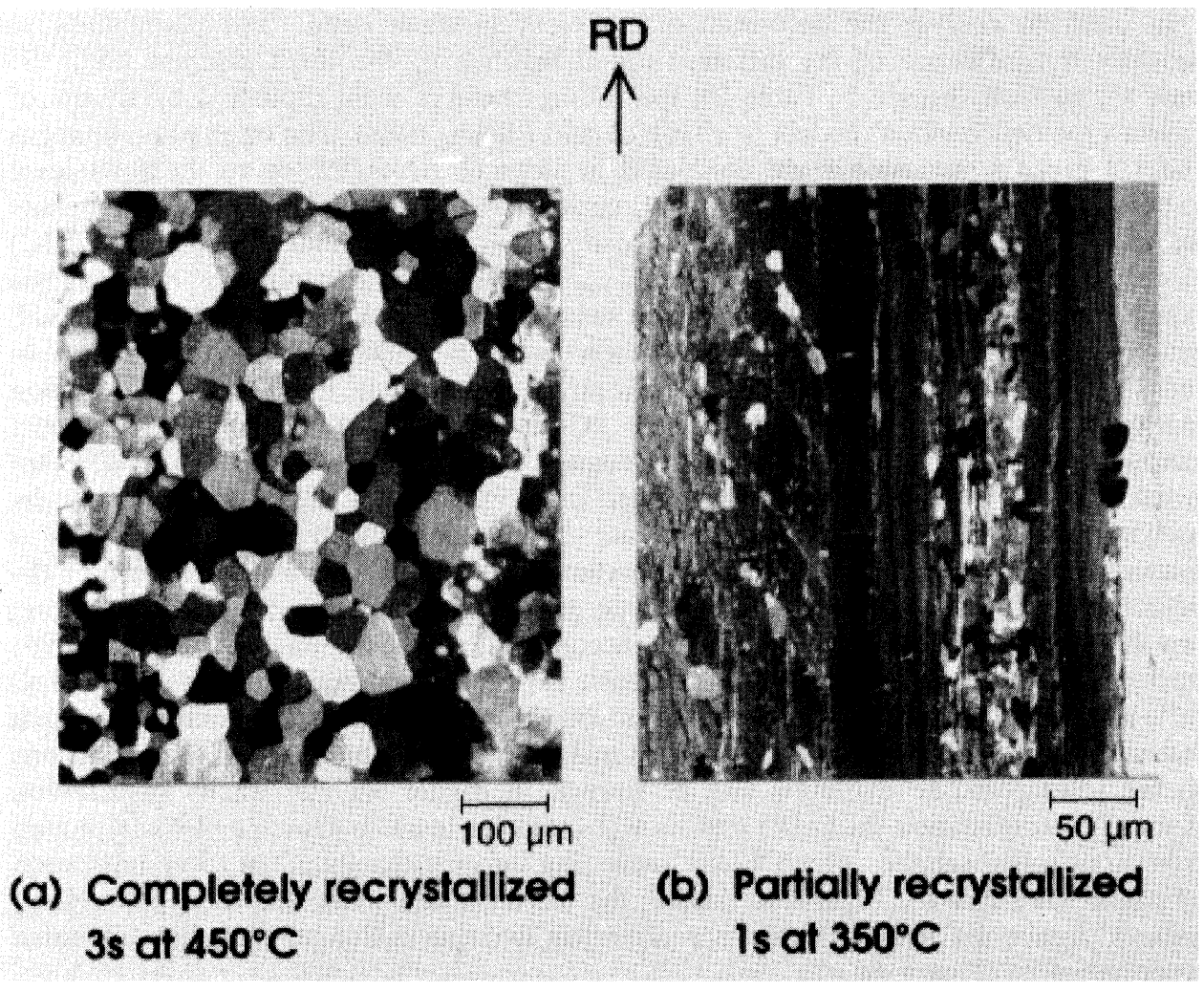

Figure 7 Micrographs of the recrystallized samples A100 "C" (90\% red., anodically oxidized; note different magnification)

(a) completely recrystallized $\left(3 \mathrm{~s}\right.$ at $\left.450^{\circ} \mathrm{C}\right)$, (b) partially recrystallized $\left(1 \mathrm{~s}\right.$ at $\left.350^{\circ} \mathrm{C}\right)$ 


\section{DISCUSSION}

\subsection{Influence of the initial grain size on the rolling textures}

As shown in Sec. 3.1, in general all samples investigated exhibit fcc rolling textures characterized by the typical $\beta$-fibre (Figure 2). With regard to the various sample stages, however, two effects have to be considered: (i) Differences in the distribution of the orientations along the $\beta$-fibre. Whereas in all sample stages of the overaged series A100 a strong C-orientation prevailed (Figure $2 b$ ), in samples " $S$ " and " $C$ " of the peak-aged series A1 a shift of the texture maximum from the C-towards the B-orientation was observed with increasing deformation (Figure 2a). (ii) Differences in the texture sharpness, i.e. in the height of the $\beta$-fibres: In order to take the different textures (Figure 2 ) into account, the so called texture index $J$ as a measure of the general texture sharpness was computed from the texture data $f(g)$ according to $J=\oint[f(g)]^{2} \mathrm{~d} g$ (Bunge 1969). In Figure $8 a$ and $b$ the evolution of $J$ with increasing deformation is shown for the fine grained samples "F" and the coarse grained samples " $C$ " of series A1 and A100, respectively, which will be discussed later.

In order to analyse the deformation behaviour in more detail, and particularly to consider the influence of the different initial textures of the three samples " $F$ ", " $S$ " and "C" as well (Figure 1, Table 2), the rolling textures were modelled by means of Taylor type deformation models (e.g. Hirsch and Lücke, 1988). The orientation changes under a given strain state $\varepsilon$ are computed in steps of $\Delta \varepsilon=0.025$ up to the final level of deformation. In the classical Taylor full constraints (FC) model all shear components are zero, i.e. $\varepsilon_{\mathrm{RD} / \mathrm{ND}}, \varepsilon_{\mathrm{TD} / \mathrm{ND}}$ and $\varepsilon_{\mathrm{RD} / \mathrm{TD}}$. Mostly, however, the relaxed constraints (RC) model with the free shears $\varepsilon_{\mathrm{RD} / \mathrm{TD}}$ and $\varepsilon_{\mathrm{TD} / \mathrm{ND}}$ yields better resemblance between the experimentally observed and the predicted textures. Finally, a new model was applied, which under consideration of the interaction between neighbouring grains allows to deduce the amount of shear relaxation in a physical way from the gain in deformation energy between the two limiting cases, FC-model (no relaxation) and RC-model (complete relaxation of all three shears)(Wagner, 1994). The influence of the different initial textures of the three samples under investigation was taken into account by applying these models to $\sim 750$ individual orientations which were derived by a discretization of the corresponding initial textures (Figure 1). After the simulation ODFs were calculated by associating a Gauss type scatter (scatter width $5^{\circ}$ ) to the resulting new orientations ( $c f$. Sec. 2). The ODFs according to the new model (Wagner 1994) are represented in Figure 9a in terms of their $\beta$-fibre plots after simulating up to $\varepsilon=3$ $(95 \%)$. As usually found, the general texture sharpness of the modelled textures is much sharper than of the experimental rolling textures (Figure 2a,b), but qualitative conclusions on the rolling texture evolution can be drawn. In Figure $9 \mathrm{~b}$ the density distribution of the Cube-orientation (at $\phi=0^{\circ}$ ) and its RD-rotations towards Goss $\left(\phi=45^{\circ}\right)$ is plotted for various rolled samples which yields interesting information about the recrystallization behaviour (see below). Figure 8c depicts the texture index $J$ for the modelled rolling textures. Again, the absolute values are more than two times stronger than those obtained experimentally (Figure 8a,b).

For the peak-aged samples $A 1$ a general texture weakening was observed with increasing initial grain size, as is apparent from the weaker $\beta$-fibres (Figure 2a) as well as from the lower values of the texture index $J$ (Figure 8a). Moreover, with increasing deformation in samples " $S$ " and " $C$ " an orientation shift of the texture maximum from the $\mathrm{C}$ - to the B-orientation was found (Figure 2a). Both effects, the 
INFLUENCE OF THE INITIAL GRAIN SIZE
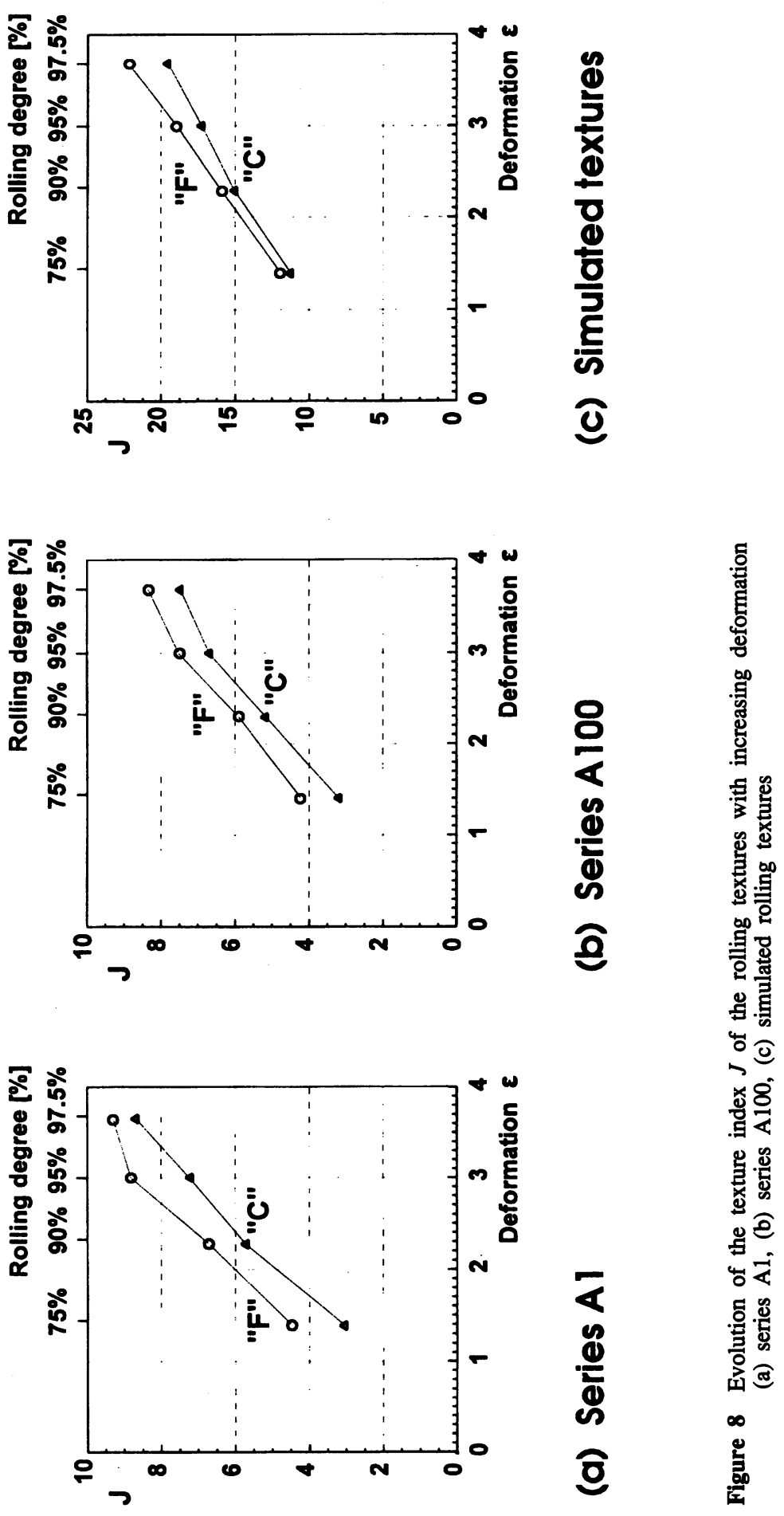

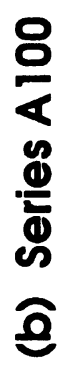


orientation shift towards B and the texture weakening with increasing initial grain size, had also been predicted by the model calculations considering the differences in the initial textures (Figure 9a); but in the models both effects were substantially less pronounced than those obtained experimentally. Thus both effects are at least partially caused by the differences in the initial grain size of the samples and not only by their different initial textures.

The orientation shift from the C- towards the B-orientation can be attributed to shear band formation in samples containing small shearable precipitates (Figure 3a-c), as already discussed earlier (Engler et al. 1989, Lücke and Engler 1990). In general, with increasing deformation and with increasing initial grain size more shear bands form (e.g. Korbel et al. 1986, Duggan et al. 1993), as could be confirmed in the present study (Figure 3a-c; Sec. 3.1). Consequently, the increase of B at the expense of C is much less pronounced in the originally fine grained sample "F" (Figure 2a). A retardation of the rolling texture development in coarse grained material has already been described by Juul Jensen et al. (1986), Leffers et al. (1987) and Sindel et al. (1990). It can be explained by differences in the flow pattern: In coarse grained samples generally a higher level of deformation heterogeneities exists, as e.g. deformation bands, splitting of orientations and, of course, the shear bands, which counteracts the formation of a sharp rolling texture (cf. Lee and Duggan 1993). These effects result in a deformation mode rather according to the relaxed constraints (RC) model and in an

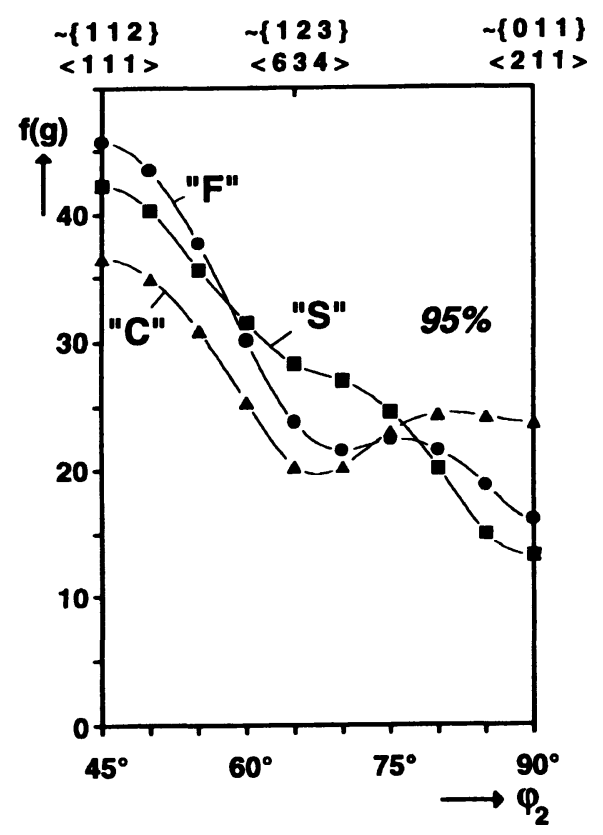

(a) $\beta$-fibres

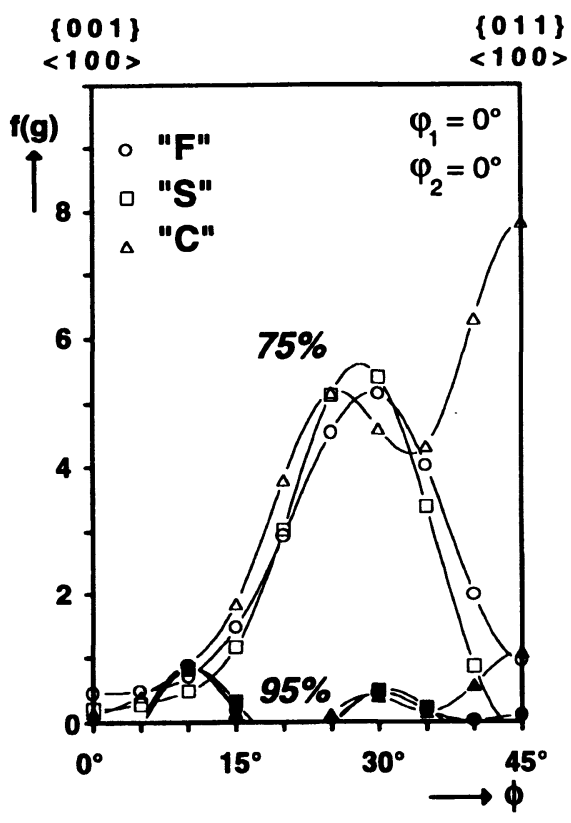

(b) Cube RD-Rotation

Figure 9 Simulated rolling textures; (a) $\beta$-fibres, (b) Cube RD-rotation 
increase of the B-orientation (Lee and Duggan 1993, Wagner 1994). This fact is apparent from the position of the $\beta$-fibres $\varphi_{1}=f\left(\varphi_{2}\right)$ and $\phi=f\left(\varphi_{2}\right)$ in the Euler angle space (Figure 2c): The curves of the coarse grained sample " $C$ " (open triangles) lie closer to those computed by means of the Taylor RC-model, whereas those of the fine grained sample "F" (filled triangles) correspond closer to the FC-model (Figure 2c).

In case of the overaged samples A100, in contrast, a strong C-orientation develops during rolling, which, relatively to the other $\beta$-fibre components, is even more pronounced than in the simulated textures (Figure 9a). Furthermore, a much smaller influence of the initial grain size is obtained as compared to the samples A1. At $75 \%$ deformation a slightly sharper texture is still found in samples " $F$ " and " $S$ " compared to sample "C" (Figure 2b, open symbols), at 95\%, however, this advantage of the fine grained samples has disappeared and the texture maxima exhibit only some unsystematic scatter (Figure 2b, filled symbols) which is caused by the large initial grain size (see above). Similarly, the differences of the texture index $J$ in dependence on the initial grain size are smaller in the overaged samples A100 than for the samples A1, but are comparable to those predicted by the model calculations (Figure 8c). Conclusively, the slight decrease of the texture sharpness with increasing initial grain size in the samples A100 is mainly caused by the different initial textures and not by the initial grain size.

These two results, the strong $\mathrm{C}$-orientation and the low dependence on the initial grain size, must be attributed to the $\theta^{\prime}-\mathrm{Al}_{2} \mathrm{Cu}$-precipitates in the overaged samples $\mathrm{A} 100$ : In the presence of a high density of finely dispersed non-shearable particles the spacing between the particles is much more important for the dislocation slip than the initial grain size of the sample. The interparticle spacing, however, is similar in all samples " $F$ ", "S" and " $C$ ", and thus, no influence of the initial grain size is to be expected. Thus, the $\theta^{\prime}-\mathrm{Al}_{2} \mathrm{Cu}$-precipitates cause a homogenization of deformation, corresponding e.g. to an extremely fine grained material. This results in a more Taylor FC-like deformation mode (Engler et al. 1989) as is evident from the observation that the position of the $\beta$-fibres (Figure 2c) of the samples A100 (filled symbols) lies closer to the curves computed by means of the FC-model than the values of series A1 (open symbols). Furthermore, in contrast to the samples A1 only minor differences in the position of the $\beta$-fibres between samples $A 100$ "F" and " $C$ " were observed.

\subsection{Influence of the initial grain size on particle stimulated nucleation (series A100)}

As already described in the introduction, the recrystallization textures of Al-alloys containing large particles which favour PSN can, in a first approximation, be interpreted by $40^{\circ}<111>$ - growth selection out of a random spectrum of nucleus orientations (type $\mathrm{R} 3, c f$. Sec. 1). In that case, the resulting recrystallization textures can be simulated by a numerical $40^{\circ}<111>$ - transformation of the corresponding rolling texture. In Figure 10 an example is shown for the coarse grained sample " $\mathrm{C}$ " rolled $97.5 \%$ (cf. Figure 5d). However, in the samples with a smaller initial grain size occupations of Cubeand RD-rotated Cube-orientations were observed (Figures 5a,c, 6b,d) that were much stronger than in the corresponding transformed rolling textures, and therefore, the resemblance between recrystallization and transformation texture in these cases is less good. Since these differences particularly concern the Cube and the ND-rotated Cubeorientations, they can clearly be examined by plotting the intensity distribution along the line between the Cube- and the $45^{\circ} \mathrm{ND}$-rotated Cube in the Euler angle space, i.e. along $\varphi_{1}$ for $\phi=\varphi_{2}=0^{\circ}$. In Figure 11a this is shown for the samples rolled 95\%. Again, 


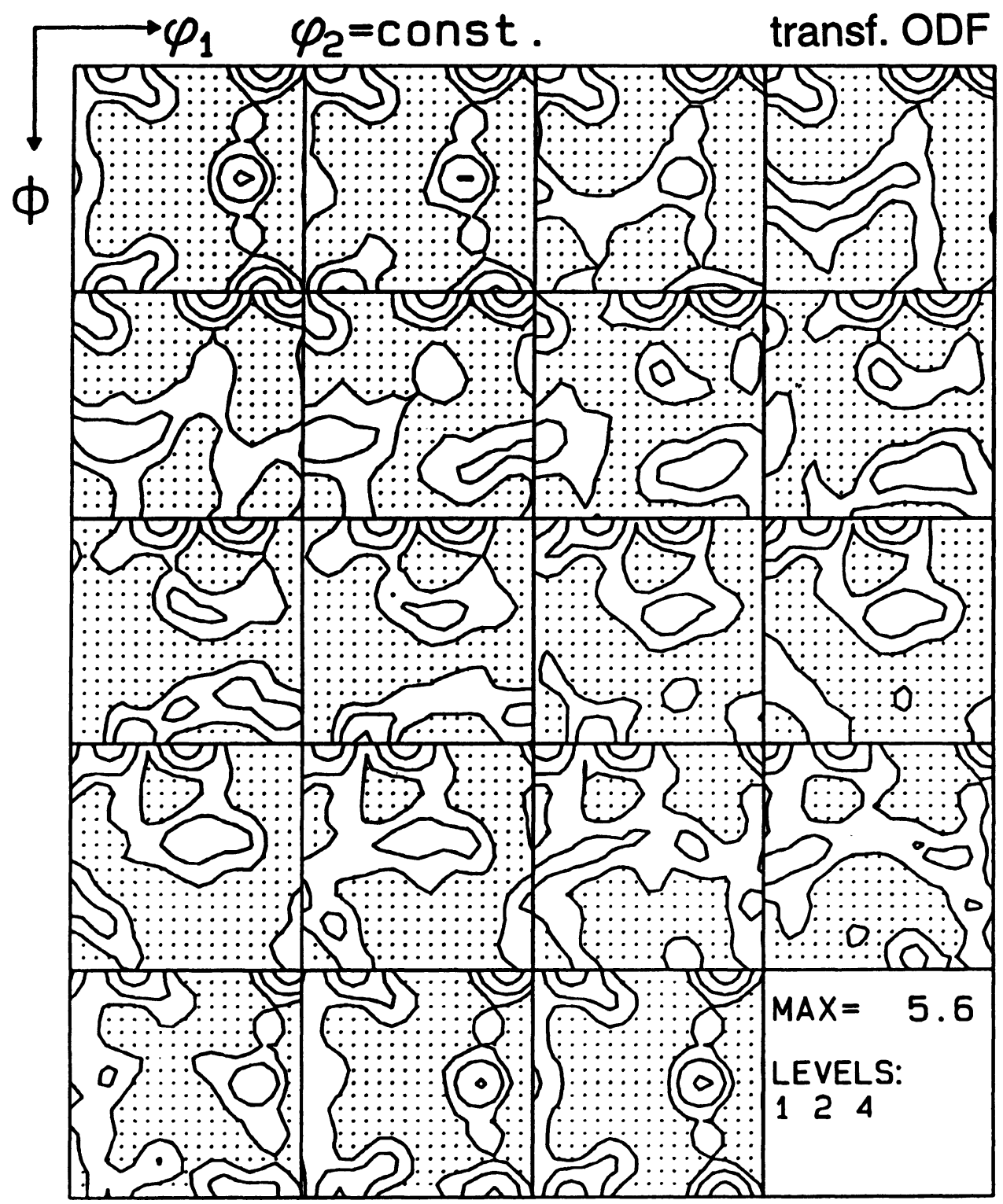

Figure $1040^{\circ}<111>$-transformed rolling texture of sample $\mathrm{A} 100$ "C" (97.5\% red.). 
the strong decrease of the orientation density in the exact Cube-position $\left(\varphi_{1}=0^{\circ}\right)$ with increasing initial grain size is apparent (cf. Figures 5, 6b,d). Vice versa, however, the ND-rotated Cube-orientations increase, which yields a better resemblance with the corresponding transformed rolling textures (Figure 10 and squares in Figure 11b).

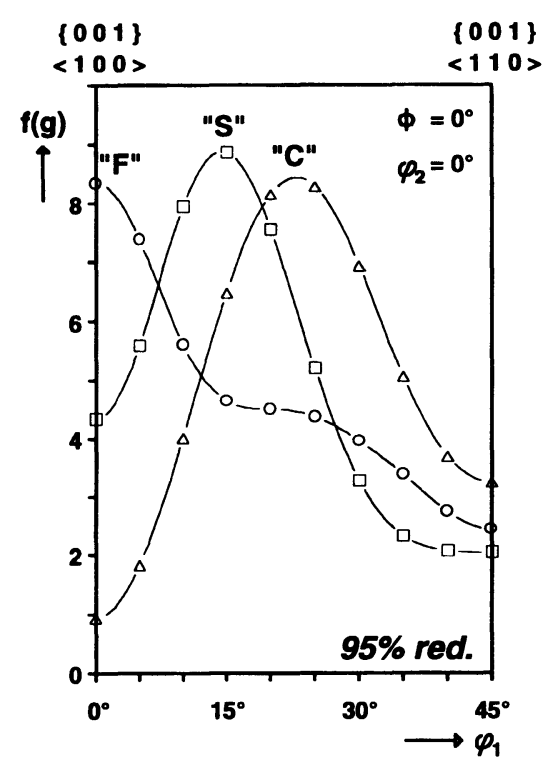

(a) Recrystallization textures

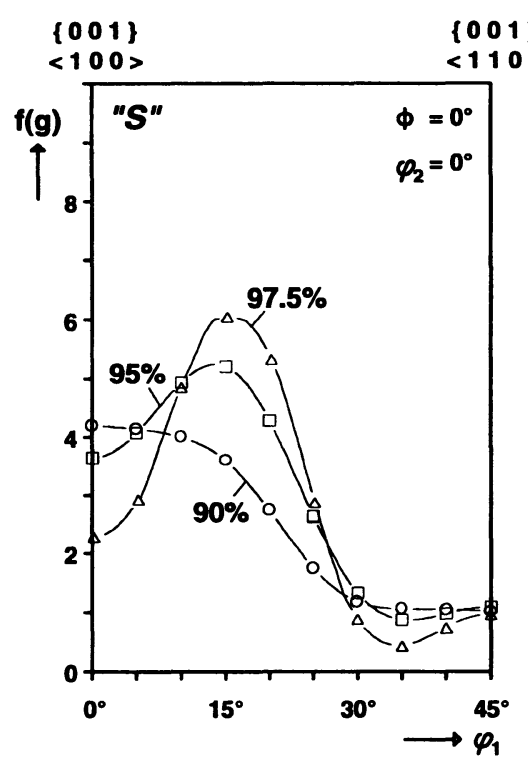

(b) Transformation textures

Figure 11 Orientation density distribution of Cube- and ND-rotated Cube-orientation of the recrystallized sample A100

(a) experimental recrystallization textures (95\% red.)

(b) transformed rolling textures (sample "S").

Microstructural investigations of a binary $\mathrm{Al}-1.3 \% \mathrm{Mn}$ alloy with a similar precipitation state and a small initial grain size $(40 \mu \mathrm{m})$ have shown that two nucleation mechanisms were active (Engler et al. 1995b). By means of microtexture analysis using CBED and EBSD it could furthermore be proved that nucleation of Cube-oriented grains takes place at the Cube bands, whereas PSN led to grains with a rather weak orientation distribution and some preference of $\mathrm{Cube}_{\mathrm{ND}}$ - and P-orientations. The superposition of these two nucleation mechanisms then caused the formation of a mixed texture between that of single phase Al-alloys comprising only the Cube-orientation with its RD-scatter (type R1; cf. Sec. 1) and the $40^{\circ}<111>$ - transformed rolling texture (R3). With increasing volume of precipitated $\mathrm{Al}_{6} \mathrm{Mn}$-particles the efficiency of PSN increased. In the macrotextures this resulted in a reduced intensity of the Cube-orientation, and instead, occupations of the ND-scattered Cube-orientation, the P-orientation and generally a larger part of random orientations arose. So, the formation of recrystallization textures in dependence on the particle volume proceeded very similar as observed in the present $\mathrm{Al}-\mathrm{Cu}$ samples in dependence on the initial grain size. Consequently, it could be concluded that an increased initial grain size favours PSN as well, and so no further local texture measurements had been carried out for the sample series A100. 
As already briefly described in Sec. 1, Cube-oriented grains are known to nucleate at band-like structures present in the deformed microstructure. According to the mechanism originally proposed by Dillamore and Katoh (1974), nucleation takes place in the transition bands between two divergent orientation zones. However, it is not yet certain whether the spatial density of nuclei in these transition bands is sufficient to explain the occurrence of a strong Cube-texture. Therefore, it has been argued that the Cube-orientation originates from deformed grains which after the rolling process exhibit an orientation close at Cube (Weiland and Hirsch 1991, Daaland et al. 1992). The Cubeand particularly the RD-scattered Cube-orientation are metastable under rolling conditions, which means that Cube-oriented grains from the initial texture can retain their orientation, so that even after high degrees of reduction still band-like regions containing the Cube-orientation are present in the deformed microstructure. This fact was confirmed by a simulation of the rolling textures with the help of an improved Taylor model, as described above (Sec. 4.1). Starting from the initial textures (Figure 1), these calculations predicted occupations of RD-scattered Cube for all rolling degrees (Figure 9b).

The formation of a transition band between two parts of an old grain with a splitting orientation according to the Dillamore/Katoh-mechanism will give rise to a reduction of the average band thickness compared to the values which can simply be computed under assumption of a homogeneous thickness reduction. In the present samples indeed strongly scattering band thicknesses below the values obtained for homogeneous reduction were observed (Figure 3, Sec. 3.1), which might indicate the occurrence of transition bands. However, in particular in the fine grained samples the nucleation of Cube-grains at these transition bands seems to be rather unlikely: Heavy deformation of a structure with an initial grain size of $40 \mu \mathrm{m}$ (sample " $F$ ") leads to an average band thickness of only several $\mu \mathrm{m}$ after rolling, and the formation of transition band would then give rise to very thin bands with a thickness smaller than the critical nucleus size. On the other hand, regarding the observed constant volume fraction of Cube after rolling (Figure 9b), the arrangement in thin bands in the fine grained samples would yield a larger number of such bands and, consequently, seems to be more favourable for nucleation of Cube than in the coarse grained samples.

However, irrespective of their formation mechanism, in micrographs obtained by light microscopy (e.g. Figure 3) or SEM both types of Cube-bands will similarly show up as band-like structures parallel to $\mathrm{RD}$, which cannot be distinguished from each other or from the original grain boundaries. Consequently, nucleation of Cube-grains was always observed at such features (e.g. Figure $7 \mathrm{~b}$ (series A1), Duggan et al. (1993) and Engler et al. 1995b). Therefore, these features were subsumed by Duggan et al. (1993) under the term "interfaces parallel to the rolling plane". The sharpness of the Cubeorientation, however, is strongly depending on the number of the available Cubenucleation sites and, consequently, by the spacing between these interfaces (see sketch Figure 12). In the coarse grained samples "C" only very few interfaces can be observed across the sheet thickness (Figure 3c,d). Thus, regardless of the origin of these bands, only few Cube-nuclei can be formed (Figure 12b) and the recrystallization texture is mainly controlled by PSN. In the samples with smaller initial grain sizes " $S$ " and particularly " $F$ ", the band-like structures are more narrow spaced (Figure 3a,b). Consequently the number of Cube-grains increases to the disadvantage of grains stemming from PSN (Figure 12a). In the macrotextures (Figure 5, 6b,d) this causes the observed sharpening of the Cube-texture at the cost of the orientations attributed to PSN ("Nucl.") and of the random orientations (phon). 
On the other hand, the formation of an ideal $40^{\circ}<111>$ transformed rolling texture (type R3) by PSN is favoured by large grain sizes: In the coarse grained samples even after heavy deformation the deformed grains are rather thick (e.g. Figure 3d). Under assumption of homogeneous thickness reduction by $90 \%$ the bands in sample "C" and "S" are $80 \mu \mathrm{m}$ and $20 \mu \mathrm{m}$ thick, respectively (see above). Consequently, these thick bands can contain several $\theta$ '-particles (size $\sim 1 \mu \mathrm{m}$ ) across the grain thickness, and the assumption of growth selection out of a random spectrum of nucleus orientations as required for obtaining a transformed rolling texture is reasonable, which in fact shows up in the good resemblance between Figure 5d and Figure 10. In the fine grained sample "F", in contrast, the microstructure is substantially finer with an average band thickness of only $\sim 4 \mu \mathrm{m}$. In this case obviously worse conditions for obtaining the transformed rolling texture are present and other nucleation mechanisms (i.e. Cube-bands, see above) will take over, finally dominating the recrystallization texture.

Conclusively, the recrystallization texture emerges from a superposition of orientations stemming from the various nucleation sites, i.e. Cube-bands and precipitates. This explanation is confirmed by the examination of the grain size data after complete recrystallization (cf. Sec. 3.2): It was found that the size of the recrystallized grains did virtually not depend on the initial grain size of the samples. Thus, irrespective of the nucleation mechanism, an equal number of nucleation events is given in all samples independent on the initial grain size.

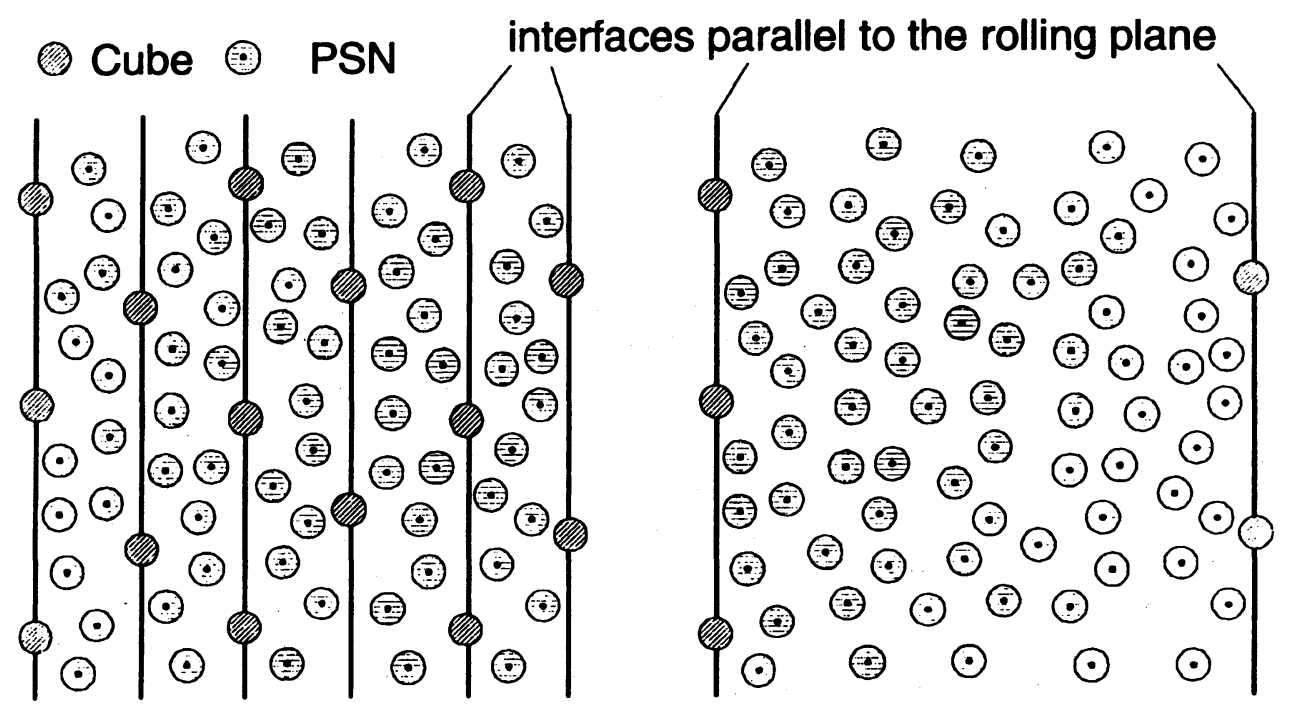

(a) Fine grained

(b) Coarse grained

Figure 12 Schematic sketch of the spatial distribution of Cube- and PSN-grains (see text.) (a) fine grained material, (b) coarse grained material. 
It must be emphasized that the reduction of the Cube-orientation with increasing initial grain size can neither be explained by the variations in the initial texture prior to cold rolling (Figure 1) nor by the different rolling textures (Figure 2): In all simulated rolling textures (see above) equal occupations of the RD-rotated Cube-orientation arose, irrespective of the initial texture (Figure 9b). Consequently, an equal number of potential nucleation sites has to be assumed which should cause equal intensities of the Cubeorientation. The differences in the textures after the rolling deformation of samples " $F$ ", " $S$ " and " $C$ " are rather low (Figure 2b, cf. Sec. 3.1 and 4.1). Consequently, the transformation textures are very similar which, following the above discussion, should result in similar recrystallization textures. Both points, however, are in contrast to the results found experimentally.

With increasing deformation the rolling texture substantially sharpened (Figure $2 b$ ). Consequently, the components in the transformation texture being attributed to PSN $\left(\mathrm{Cube}_{\mathrm{ND}}, \mathrm{P}\right)$ increased, which is consistent with the experimental observation of the volume fraction of these orientation ("Nucl.") increasing at the expense of the random part in the final recrystallization textures (Figure 6b,d). On the other hand, the volume fraction of the exact Cube-orientation slightly decreased with increasing deformation. However, in the simulated rolling textures (Figure 9b) as well as in the transformation textures (Figure 11b) less Cube-orientations were obtained, which means than both the nucleation and the growth conditions of Cube are less favoured at higher deformation degrees.

\subsection{Influence of the initial grain size on the nucleation at shear bands (series A1)}

In the samples of the peak-aged series A1 strong occupations of the Goss-, Q- and P-orientations prevail, which are much stronger than found by a simple $40^{\circ}<111>$ transformation of the corresponding rolling texture (see above). This indicates the additional preferred nucleation of these orientations at shear bands (Figure $7 \mathrm{~b}$ ), as discussed by Engler et al. (1995). Additionally, however, in all samples occupations of the Cube-orientation were observed, which are particularly strong in the fine grained sample " $F$ ". Therefore, as in the overaged samples, it can be concluded that the final recrystallization texture emerges from a competition of grains nucleating at Cube-bands and grains stemming from the shear bands (cf. Koken et al. 1988).

In order to confirm this interpretation, local texture measurements of the new recrystallized grains stemming from the two different nucleation sites were performed in partially recrystallized samples by means of EBSD (Sec. 2). However, as already mentioned before, the time necessary for complete recrystallization was very short $(<3 \mathrm{~s})$, so that partially recrystallized stages could not be achieved for samples where these effects seem to exert a strong influence on the recrystallization textures, i.e. where the characteristic Goss- and Q-orientations emerged. Nucleation at shear bands could only be studied in sample " $C$ ", which had been deformed $90 \%$ and subsequently annealed for $\sim 1 \mathrm{~s}$ at $350^{\circ} \mathrm{C}$ (Figure $7 \mathrm{~b}$ ). The reduction of the annealing temperature was checked to have no significant effect on the resulting texture after complete recrystallization (Figure 13a; cf. Figure 4b).

The measured single grain orientations of this sample were related to the nucleation sites of the corresponding grains, i.e. grains either nucleating at shear bands or nucleating at band-like structures parallel to RD (Cube-bands, grain boundaries). From the two data sets ODFs were calculated as described in Sec. 2, the corresponding $\varphi_{2}=0^{\circ}$-sections are represented in Figure 13b,c. Although the number of encountered grains was much 
too small for a quantitative reproduction of an ODF, at least qualitative conclusions about the orientation distributions related to the respective nucleation sites can be drawn from these diagrams: The orientation distribution of the new grains stemming from the shear bands (Figure 13b) is rather similar to the corresponding macrotexture (Figure 13a), however, with notably less occupations of the exact Cube-orientation. In contrast, the new grains stemming from the Cube-bands parallel to RD mostly exhibited the Cube-orientation with only minor scatter (Figure 13c).

In the classification of the recrystallization texture components with respect to their nucleation sites (Figure 6) the P-orientation was integrated into the orientations which nucleate at the shear bands, as proposed by Engler $e$ t al. (1995). However, the intensity of the P-orientation exhibits an opposite behaviour as to the other orientations nucleating at the shear bands, i.e. Goss and Q: With increasing initial grain size the intensity of the P-orientation decreases (Figure 4) which would contradict the assumption of its nucleation in the shear bands. However, in the EBSD local texture measurements of grains stemming from the shear bands occupations of an orientation $\sim\{011\}<110>$ situated rather close to the P-orientation were found in the coarse grained sample " $C$ " (Figure 13b) which resemble the corresponding macrotexture data (Figures 4b, 13a). Conclusively, the assumption of a possible nucleation of the P-orientation at shear bands (besides PSN in the overaged samples!) still holds, although the exact mechanisms needs further clarification.

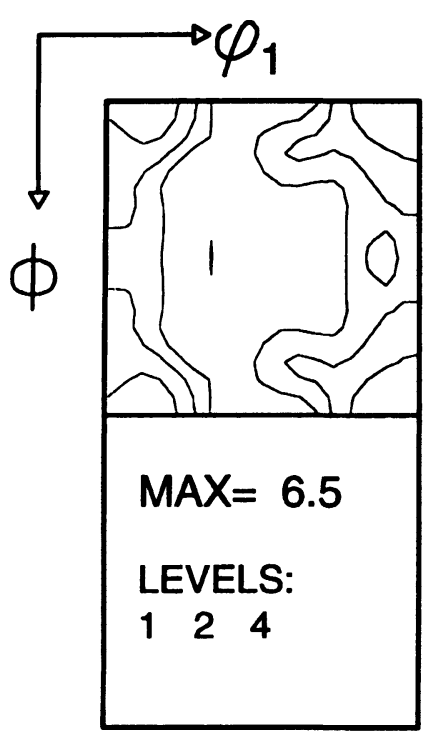

(a) X-ray macrotexture $\varphi_{2}=0^{\circ}$

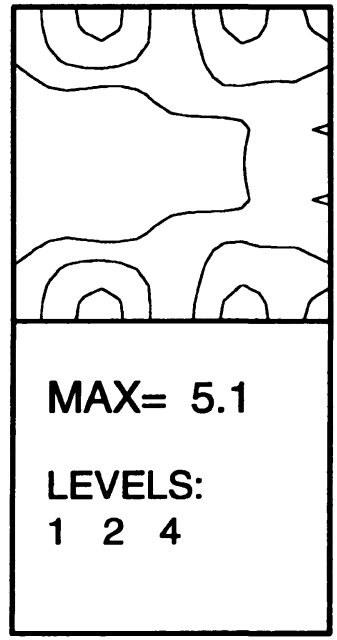

(b) EBSD shear bands
GAUSS ODF

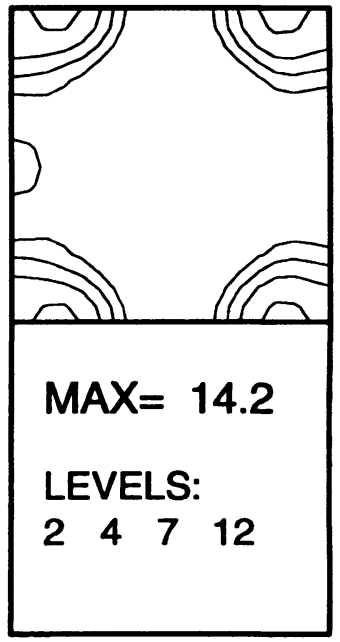

(c) EBSD Cube-bands

Figure 13 Textures after annealing of sample A1 "C" (90\% red., $\varphi_{2}=0^{\circ}$-sections)

(a) X-ray macrotexture after complete recrystallization (annealed for $5 \mathrm{~s}$ at $350^{\circ} \mathrm{C}$ ),

(b) EBSD-local texture of grains stemming from shear bands,

(c) EBSD-local texture of grains stemming from Cube-bands. 
In contrast to the potential nucleation sites at the large $\theta^{\prime}$-particles in series $\mathbf{A} 100$, it must be considered that the density of shear bands strongly depends on both the initial grain size and the deformation degree. As discussed above (Sec. 4.1), with increasing deformation and increasing initial grain size more shear bands form (Figure 3a-c). Consequently, the number of possible nucleation sites at shear bands increases as well, which causes an increase of the volume fraction of the shear band orientations and a simultaneous decrease of the Cube-orientation. The shear bands themselves even reduce the number of potential Cube-nuclei by destroying the Cube-bands (Ridha and Hutchinson 1982). Thus these effects overlap those caused by the reduced number of Cube-nuclei as discussed above.

\section{CONCLUSIONS}

The influence of the initial grain size on the development of the rolling and recrystallization textures was investigated in the binary alloy $\mathrm{Al}-1.8 \% \mathrm{Cu}$. Two different sample stages were produced in order to ensure different mechanisms of recrystallization nucleation: (i) One series of samples was peak-aged which led to the precipitation of very fine particles. During rolling these precipitates gave rise to shear band formation and, during subsequent annealing, to recrystallization nucleation at the shear bands. (ii) The other sample series was overaged so as to precipitate large $(\sim 1 \mu \mathrm{m}) \mathrm{Al}_{2} \mathrm{Cu}-\theta^{\prime}-$ particles, which during annealing yielded particle stimulated nucleation (PSN). Generally it was found that a reduced initial grain size prior to cold rolling favours the formation of the Cube-orientation at the expense of the orientations stemming from the shear bands or precipitates. In particular, the following conclusions can be drawn:

o During rolling of the peak-aged samples a strong shear band formation shows up. With increasing initial grain size the tendency to form shear bands substantially increases. In the rolling textures this results in an increasing orientation shift of the texture maximum from the $\mathrm{C}$-orientation along the $\beta$-fibre towards the $\mathrm{B}$ orientation. The overaged samples, in contrast, depict homogeneous Taylor-like deformation which yields a rolling texture with a strong C-orientation.

o With regard to the texture sharpness, an increasing initial grain size leads to weaker rolling textures in the peak-aged samples A1. This is attributed to differences in the microstructural evolution. The larger the grains are, the more deformation heterogeneities form which counteracts the formation of a sharp rolling texture. In samples A100 containing large particles, the free length of dislocation slip is affected by the spacing between the particles rather than by the grain size, and therefore, the effect of a retardation of the rolling texture evolution with increasing initial grain size is less pronounced.

o During recrystallization annealing two possible nucleation sites are active in the overaged sample series A100: As found in homogeneously deforming $\mathrm{Al}$-alloys, recrystallization nucleation can take place at band-like structures which mainly exhibit the Cube-orientation. Additionally, PSN takes place so that the recrystallization textures are assembled from a superposition of the Cube-orientation and the orientations of grains stemming from PSN. With increasing initial grain size the volume fraction of orientations which are assumed to nucleate at precipitates 
strongly increases to the disadvantage of the Cube-orientation. This is explained by the larger distance between the Cube-bands, and consequently, by the lower number of available Cube nuclei in the coarse grained samples.

o In the peak-aged samples A1 very similar results show up. In this case, a competition between the Cube-oriented grains and grains nucleating at the shear bands takes place, with the latter exhibiting mainly Goss- and Q-orientation. It must be further considered that besides the variation in the spatial density of potential Cube-oriented nuclei (as in the overaged samples) the shear band formation during rolling of the peak-aged samples strongly increased with initial grain size, which during recrystallization additionally favours shear band orientations rather than the Cubeorientation.

\section{Acknowledgements}

The author likes to thank Dr. P. Wagner for helpful discussions and for making available his computer code. Stimulating discussions with P. Yang, MSC., and Dr. W. Mao are also gratefully acknowledged.

\section{References}

1. Bleck, W. and Bunge, H. J. (1981). Acta Metall. 29, 1401-1412.

2. Bunge, H. J. (1969). "Mathematische Methoden der Texturanalyse", Akademie, Berlin.

3. Daaland, O., Maurice, C., Driver, J., Raynaud, G.-M., Lequeu, P., Strid, J. and Nes, E. (1992). Proc, 3rd Int. Conf. on Al-Alloys (ICAA 3), (eds. L. Amberg et al.), The Norwegian Inst. of Tech., Trondheim, Vol.II, 297-304.

4. Dillamore, I. L. and Katoh, H. (1974). Metal Sci. 8, 73-83.

5. Doherty, R. D., Kashyap, K. and Panchanadeeswaran, S. (1993). Acta Metall. Mater. 41, 3029 3053.

6. Dons, A. L. and Nes, E. (1986). Mater. Sci. Tech. 2, 8-18.

7. Duggan, B. J. and Chung C. Y. (1994). Proc. ICOTOM 10, Mat. Sci. Forum 157-162, 17651770 .

8. Duggan, B. J., Lücke. K., Köhlhoff, G. D. and Lee C. S. (1993). Proc. Recrystallization '92, Mat. Sci. Forum 113-115, 121-126.

9. Engler, O. and Gottstein, G. (1992). Steel Research 63, 413-418.

10. Engler, O., Hirsch, J. and Lücke, K. (1989). Acta Metall. 37, 2743-2753.

11. Engler, O., Hirsch, J. and Lücke, K. (1995). Acta Metall. Mater. 43, 121-138.

12. Engler, O., Yang, P. and Kong, X. W. (1995b). submitted to Acta Metall. Mater.

13. Hirsch, J. and Lücke, K. (1986). Proc. 7th Risø Int. Symp. (eds. N. Hansen et al.) Risø Nat. Lab., Roskilde, 361-366.

14. Hirsch, J. and Lücke, K. (1988). Acta Metall. 36, 2883-2904.

15. Hirsch, J., Burmeister, G., Hoenen, L. and Lücke, K. (1986). in "Experimental Techniques of Texture Analysis", (ed. H.J. Bunge), DGM, Oberursel, 63-71.

16. Hjelen, J., Ørsund, R. and Nes, E. (1991). Acta Metall. Mater. 39, 1377-1404.

17. Humphreys, F. J. (1977). Acta Metall. 25, 1323-1344.

18. Juul Jensen, D., Hansen, N. and Humphreys, F. J. (1985). Acta Metall. 33, 2155-2162.

19. Juul Jensen, D., Hansen, N. and Humphreys, F. J. (1988). Proc. ICOTOM 8, (eds. J.S. Kallend, G. Gottstein), TMS Warrendale, 431-444.

20. Koken, E., Embury, J. D., Ramachandran, T.R. and Malis, T. (1988). Scripta Metall. 22, 99 103.

21. Korbel, A., Embury, J. D., Hatherly, M., Martin, P. L. and Erbslöh, H. W. (1986). Acta Metall. 34, 1999-2009.

22. Lee, C. S. and Duggan, B. J. (1993). Acta Metall. Mater. 41, 2691-2699.

23. Leffers, T., Juul Jensen, D., and Hansen, N. (1988). Proc. ICOTOM 8, (eds. J. S. Kallend, G. Gottstein), TMS Warrendale, 449-454.

24. Lücke, K. (1974). Canadian Met. Quart. 13, 261-274. 
25. Lücke, K. and Engler, O. (1990). Mater. Sci. Tech. 6, 1113-1130.

26. Lücke, K. and Engler, O. (1992). Proc. 3rd Int. Conf. on Al-Alloys (ICAA 3), (eds. L. Arnberg et al.), The Norwegian Inst. of Tech., Trondheim, Vol. III, 439-452.

27. Lücke, K., Pospiech, J., Jura, J. and Hirsch, J. (1986). Z. Metallk. 77, 312-321.

28. Oscarsson, A. (1991). Textures and Microstructures 14-18, 477-482.

29. Ridha, A.A. and Hutchinson, W. B. (1982). Acta Metall. 30, 1929-1939.

30. Sindel, M., Köhlhoff, G. D., Lücke, K. and Duggan, B. J. (1990). Textures and Microstructures $12,37-46$.

31. Wagner, P. (1994). Dissertation, RWTH Aachen.

32. Wagner, P., Engler, O. and Lücke, K. (1991). Textures and Microstructures 14-18, 927-932.

33. Weiland, H. and Hirsch, J. R. (1991). Textures and Microstructures 14-18, 647-652. 